\title{
Periodicity of Dirofilaria immitis \\ in Longterm Infections
}

Christopher C. Evans' $\bowtie$, Erica J. Burkman', Michael T. Dzimianski',

Andrew R. Moorhead', Molly D. Savadelis', Carsten Angenendt², Sven Zymny²,

Daniel Kulke 2

${ }^{1}$ Department of Infectious Diseases, College of Veterinary Medicine, University of Georgia,

Athens, GA 30602, USA

2 Bayer Animal Health GmbH, Drug Discovery, Parasiticides, Filaricides Research, 51368 Leverkusen, Germany

\section{Correspondling author:}

\section{Christopher C. Evans}

E-mail: ccevans@uga.edu

\section{Abstract}

The concentration of Dirofilaria immitis microfilariae in peripheral blood samples was measured in four experimentally infected dogs. Samples were collected at hourly intervals from $6.30 \mathrm{~h}$ to $17.30 \mathrm{~h}$ from all dogs at 11,22 , and 27 months postinfection, and at 39 months post-infection for two dogs only. Microfilarial periodicity follows the form of a simple harmonic wave over a $24 \mathrm{~h}$ period, and concentration data was fit to sine wave for each sample date to characterize changes in periodicity over time. We found the periodicity index (i.e. wave amplitude) to decrease with time $(p=0.016$, $\left.\mathrm{R}^{2}=0.97\right)$ dropping from 74.57 (95\% CI, 63.79 to $85.34)$ at 11 months post-infection to 5.55 (95\% CI, 0 to 14.82 ) at 39 months post-infection. The time of peak microfilaremia was calculated to be $17.36 \mathrm{~h}$ (95\% CI, $17.01 \mathrm{~h}$ to $18.08 \mathrm{~h}$ ) at 11 months post-infection and did not change significantly with time $\left(p=0.17, \mathrm{R}^{2}=0.70\right)$. No significant trend was observed in total microfilarial count for individual $\operatorname{dogs}(p>0.10)$. The data presented here indicate a gradual but significant loss of periodicity over the two-year study period despite maintenance of overall microfilarial levels. 


\section{Introduction}

The canine heartworm (Dirofilaria immitis) is a parasite significant in veterinary medicine for its impact on the health of domestic dogs and cats. Microfilariae (mf) are released by adult female worms in the pulmonary arteries and enter circulation where they become available to the mosquito vector during blood meals. While mf can be found in the blood at all times of the day, periodicity is also observed in which mf concentration rises and falls in a circadian cycle. This phenomenon is well-documented in related filarioid parasites Wuchereria bancrofti and Brugia malayi, and is noted to coincide with the peak feeding hours of key vector species (Hawking 1967, Abe et al. 2003). Microfilarial periodicity has also been reported in Dirofilaria repens naturally infected dogs as well as numerous heartworm infections (Church et al. 1976, Rhee et al. 1998, Ranjbar-Bahadori et al. 2011, Di Cesare et al. 2013), but to our knowledge, no longitudinal studies have been conducted in the canine host. In this study, we measured the microfilaremia of four dogs experimentally infected with D. immitis with the aim of characterizing changes in $\mathrm{mf}$ periodicity over a two-year period.

\section{Materials and Methods}

\section{Study animals and blood sample collection} Four male beagle dogs 16 to 17 weeks of age were infected with $D$. immitis L3 (2005 MO strain) provided by the Filariasis Research Reagent Resource Center (FR3; Athens, GA, USA). Each dog received a subcutaneous injection of $50 \mathrm{~L} 3$ in the right medial thigh. Nineteen days post-infection, dogs were transferred to Bayer Animal Health GmbH (Monheim, Germany) where blood samples were collected from all dogs at 11, 22, and 27 months post-infection, and at 39 months post-infection for two dogs only. Blood was collected hourly from $6.30 \mathrm{~h}$ to $17.30 \mathrm{~h}$ local time. This corresponds with the period during which blood samples are likely to be collected for research or clinical purposes. For each sample, mf were quantified by 10 thick smears of $10 \mu \mathrm{l}$ each by Giemsa staining and microscopic examination. Thick smears were prepared by mixing $40 \mu \mathrm{l}$ deionized water and $20 \mu \mathrm{l}$ heparinized blood on a glass microscope slide, allowing to air dry for at least $24 \mathrm{~h}$, and staining with Giemsa stain (mixed in a 1:9 ratio with TAE buffer) for 30 min. Microfilaria can be morphologically identified as $D$. immitis by their overall length (approximately $300 \mu \mathrm{m}$ ) and width (approximately $6 \mu \mathrm{m}$ ) which distinguishes them from other filarial species including Dirofilaria repens (approx. $370 \mu \mathrm{m} x$ $9 \mu \mathrm{m}$ ), Acanthocheilonema dracunculoides (approx. $260 \mu \mathrm{m} \times 5 \mu \mathrm{m}$ ), and Acanthocheilonema reconditum (approx. $265 \mu \mathrm{m}$ x $5 \mu \mathrm{m}$ ) (Magnis et al. 2013). Figure 1 shows a representative $D$. immitis $\mathrm{mf}$ stained in this manner.

\section{Data anallysis}

Analyses were performed on corrected mf ratios derived from raw concentrations to reduce the effect of variation in microfilaremia between animals (Sasa and Tanaka 1972). Mean mf concentration for each dog at each date post-infection was calculated. The concentrations from each of the 12 sampling times were then divided by mean $\mathrm{mf}$ concentration and multiplied by 100 to obtain $\mathrm{mf}$ ratios for each sampling time.

Microfilarial periodicity is assumed to follow a simple harmonic wave pattern as observed by Sasa and Tanaka (1972, 1974), so for each date post-infection mean $\mathrm{mf}$ ratios across all sampled dogs were fit to a sine wave equation using GraphPad Prism version 6.01 (GraphPad Software, La Jolla, CA, USA). We constrained the baseline variable to 100 , which is the average $\mathrm{mf}$ ratio across all sampling times, and constrained the period to $24 \mathrm{~h}$. We used the resulting phase shift value to calculate the time of peak microfilaremia for each sample date. Wave amplitude is equivalent to periodicity index. Linear regression analysis in Prism was performed to assess the change in peak hour and periodicity index over time with a Bonferroni 
correction applied to analyses on mean $\mathrm{mf}$ concentrations in individual animals.

\section{Results}

Mean mf concentrations measured at hourly intervals are shown in Figure 2A, represented as ratios of the mean concentration, which allows averaging among animals. Sine waves were fitted to the $\mathrm{mf}$ ratios to calculate periodicity characteristics for each sample date and are shown in Figure 2B. On the first sample date (11 months post-infection) pronounced $\mathrm{mf}$ periodicity is exhibited, with a periodicity index (i.e. amplitude) of 74.57 (95\% CI, 63.79 to 85.34) and peak concentration occurring at $17.36 \mathrm{~h}(95 \% \mathrm{CI}, 17.01 \mathrm{~h}$ to $18.08 \mathrm{~h}$; Table 1$)$. However, the periodicity index calculated by sine wave fitting was found to decrease with time $\left(p=0.016, \mathrm{R}^{2}=0.97\right)$ dropping to $5.55(95 \% \mathrm{CI}$, 0 to 14.82 ) by 39 months post-infection. Peak hour did not appear to change significantly with time $\left(p=0.17, \mathrm{R}^{2}=0.70\right)$. While measured $\mathrm{mf}$ concentrations were found to vary between individual animals, no significant trend in these levels was observed over the study period ( $p>0.10$; Table 1$)$.

\section{Discussion}

An understanding of the periodicity of $D$. immitis $\mathrm{mf}$ is useful for the timing of diagnostic sample collection and potentially for the management of transmission in the environment. In the present study, we collected microfilaremia data from experimentally infected dogs at four time intervals over a period of 28 months to characterize the dynamics of longterm infections. Over this period, we observed a significant negative trend in periodicity index with the infection apparently reaching an aperiodic state at the last time point investigated. This trend did not appear to be influenced by changes in total $\mathrm{mf}$ counts averaged over each $12 \mathrm{~h}$ sample period; while we observed an expectedly high variability between dogs, there was no consistent tendency for total $\mathrm{mf}$ levels to rise or fall over the course of this study (Table 1). Furthermore, peak hour did not change significantly with time. To our knowledge, the data from this longitudinal study represent previously unreported findings in $D$. immitis periodicity.

Canine heartworm has long been known to exhibit a circadian periodicity, with peak microfilaremia usually occurring between $16.00 \mathrm{~h}$ and $24.00 \mathrm{~h}$,

Table 1 Microfilarial periodicity characteristics at each sample date

\begin{tabular}{|c|c|c|c|c|c|c|c|}
\hline \multicolumn{2}{|c|}{ Months post-infection } & 11 & 22 & 27 & 39 & p-value & $\mathbf{R} 2$ \\
\hline \multirow{4}{*}{$\begin{array}{r}\text { Mean } \\
\text { concentration } \\
(\mathrm{mf} / \mathrm{ml})\end{array}$} & $\operatorname{Dog} 1$ & 21950 & 45957 & 62930 & 51848 & 0.25 & 0.56 \\
\hline & $\operatorname{Dog} 2$ & 6757 & 14443 & 46899 & 44229 & 0.15 & 0.72 \\
\hline & $\operatorname{Dog} 3$ & 405 & 198 & 29 & ND & 0.10 & 0.98 \\
\hline & Dog 4 & 4978 & 3869 & 14478 & ND & 0.53 & 0.45 \\
\hline \multicolumn{2}{|r|}{ Peak hour } & $17.36 \mathrm{~h}$ & $17.36 \mathrm{~h}$ & $17.34 \mathrm{~h}$ & $17.05 \mathrm{~h}$ & 0.17 & 0.70 \\
\hline \multicolumn{2}{|r|}{$(95 \% \mathrm{Cl})$} & $\begin{array}{c}\text { (17.01 to } \\
18.08 \mathrm{~h})\end{array}$ & $\begin{array}{c}(16.59 \text { to } \\
18.12 \mathrm{~h})\end{array}$ & $\begin{array}{l}(14.52 \text { to } \\
20.20 \mathrm{~h})\end{array}$ & $\begin{array}{c}\text { (10.42 to } \\
23.28 \mathrm{~h})\end{array}$ & & \\
\hline \multicolumn{2}{|c|}{ Periodicity index } & 74.57 & 53.00 & 27.43 & 5.55 & 0.016 & 0.97 \\
\hline \multicolumn{2}{|r|}{$(95 \% \mathrm{Cl})$} & $\begin{array}{c}\text { (63.79 to } \\
85.34)\end{array}$ & $\begin{array}{c}\text { (44.52 to } \\
61.48)\end{array}$ & $\begin{array}{c}\text { (7.71 to } \\
47.14)\end{array}$ & $\begin{array}{c}\text { (0.00 to } \\
14.82)\end{array}$ & & \\
\hline
\end{tabular}

ND = not done. $\quad p$-value and R2 represent non-zero slope significance and goodness of fit, respectively, of linear regression across sample dates. 


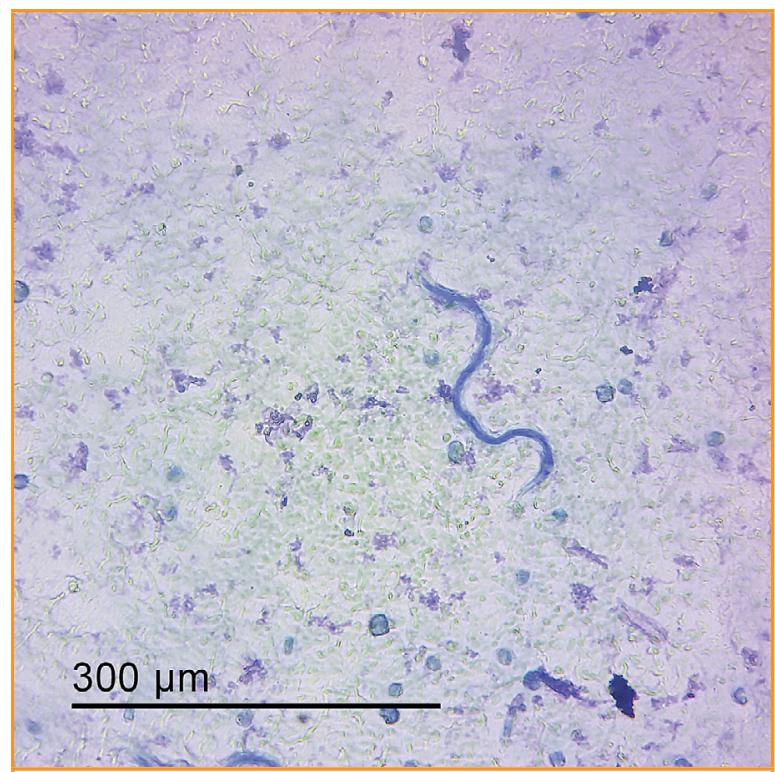

Fig. 1 Giemsa-stained Dirofilaria immitis microfilaria (400X).

seeming to vary with geographic location (Webber and Hawking 1955, Church et al. 1976, Angus 1981, Grieve and Lauria 1983, Rhee et al. 1998, Ranjbar-Bahadori et al. 2011). Because D. immitis $\mathrm{mf}$ are present in the peripheral blood throughout the day they can be characterized as subperiodic, but due to the variation in peak hour Church et al. (1976) argue that $D$. immitis cannot be accurately categorized as nocturnal or diurnal. A seasonal periodicity has also been observed with peak levels occurring in the summer months (Kume 1975, Sawyer 1975).

While it has long been observed that mf migrate from the peripheral circulation to the capillaries of the lungs, thus accounting for the observed changes in concentration, the mechanisms of periodicity remain poorly understood. The findings of basic research into the mechanisms of filarial periodicity have been extensively reviewed and predominantly indicate that one or multiple host factors are responsible for this phenomenon (Hawking 1967, Masuya 1976, Aoki et al. 2011). The timing of peak mf levels appears to coincide with peak feeding hours of the primary vector species and is most likely an adaptation to maximize uptake and transmission by the intermediate host (Hawking 1967, Tolbert and Johnson 1982, Konishi 1989). Some of the natural factors influencing periodicity are absent for laboratory animals. The dogs examined in this study remained in temperaturecontrolled housing with a constant light/dark cycle, presumably insulating them from the effects of seasonal changes. Furthermore, the D. immitis strain we used had been maintained in a laboratory setting for 14 years at the time of infection. It is easy to conceive of how differences between natural and induced heartworm infections factor into parasite behavior, and the pronounced decline in periodicity index (i.e. loss of periodicity) may be a result of these differences in conditions. Further longterm studies, ideally comparing infections with multiple strains, are necessary to gain a clearer perspective on the data presented here and may be useful in identifying key host or parasite factors affecting periodicity.

\section{Ethical approval}

All applicable international, national, and/or institutional guidelines for the care and use of animals were followed. All procedures performed in studies involving animals were in accordance with the ethical standards of the institutions at which the studies were conducted.

\section{Open Access}

This article is distributed under the terms of the Creative Commons Attribution 4.0 International License (http://creativecommons.org/licenses/ by/4.0/ ), which permits unrestricted use, distribution, and reproduction in any medium, provided you give appropriate credit to the original author(s) and the source, provide a link to the Creative Commons license, and indicate if changes were made. 


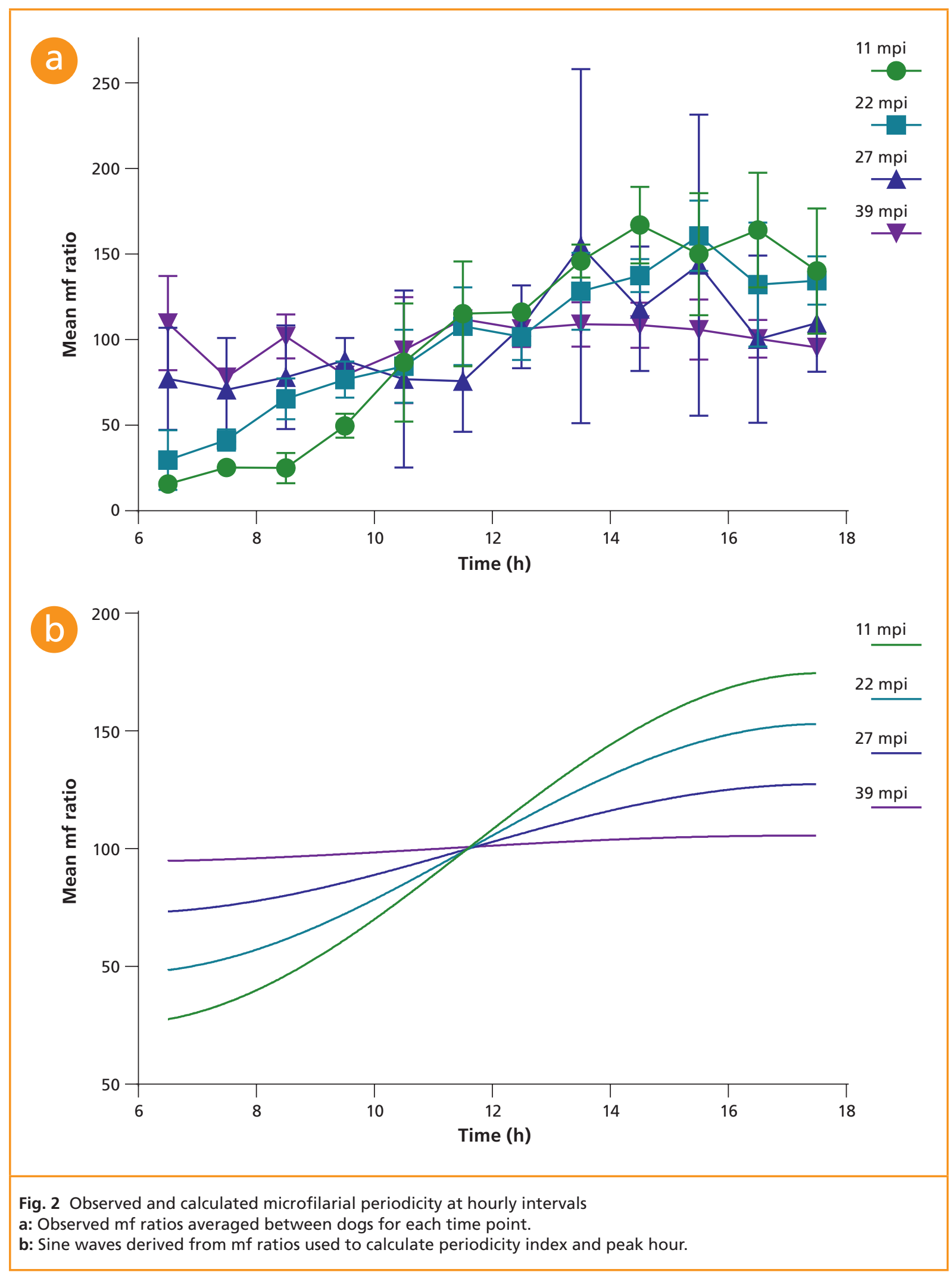




\section{References}

Abe M, Yaviong J, Taleo G, Ichimori K (2003) Microfilarial periodicity of Wuchereria bancrofti in Vanuatu. Trans R Soc Trop Med Hyg 97: 498-500

Angus BM (1981) Periodicity exhibited by microfilariae of Dirofilaria immitis in south east Queensland. Aust Vet $\mathrm{J}$ 57: 101-102

Aoki Y, Fujimaki Y, Tada I (2011) Basic studies on filaria and filariasis. Trop Med Health 39: 51-5

Church EM, Georgi JR, Robson DS (1976) Analysis of the microfilarial periodicity of Dirofilaria immitis. Cornell Vet 66: $333-346$

Di Cesare A, Otranto D, Di Giulio E, Simonato G, Latrofa MS, La Torre F, Coccia G, Traversa D (2013) Microfilarial periodicity of Dirofilaria repens in naturally infested dogs. Parasitol Res 112: 4273-4279

Grieve RB, Lauria S (1983) Periodicity of Dirofilaria immitis microfilariae in canine and murine hosts. Acta Trop 40: 121-127

Hawking F (1967) The 24-Hour periodicity of microfilariae: Biological mechanisms responsible for its production and control. Proc R Soc London Ser B Biol Sci 169: 59 LP-76

Konishi E (1989) Susceptibility of Aedes albopictus and Culex tritaeniorhynchus (Diptera: Culicidae) collected in Miki City, Japan, to Dirofilaria immitis (Spirurida: Filariidae). J Med Entomol 26: 420-424

Kume S (1975) Experimental observations on seasonal periodicity of microfilariae. , Proc Heartworm Symp 1974, 16-17 March, 1974, Auburn, Alabama, USA. (Compiled Amer Heartworm Soc). 26-31
Magnis J, Lorentz S, Guardone L, et al. (2013) Morphometric analyses of canine blood microfilariae isolated by the Knott's test enables Dirofilaria immitis and D. repens species-specific and Acanthocheilonema (syn. Dipetalonema) genus-specific diagnosis. Parasit Vectors 6: 48

Masuya T (1976) Studies on the mechanism of the filarial periodicity. The autofluorescence in the microfilariae and their periodicity. Japanese J Parasitol 25: 283-313

Ranjbar-Bahadori S, Veshgini A, Shirani D, et al. (2011) Epidemiological aspects of canine dirofilariasis in the north of iran. Iran J Parasitol 6: 73-80

Rhee JK, Yang SS, Kim HC (1998) Periodicity exhibited by Dirofilaria immitis microfilariae identified in dogs of Korea. Korean J Parasitol 36: 235-239

Sasa M, Tanaka H (1972) Studies on the methods for statistical analysis of the microfilarial periodicity survey data. Southeast Asian J Trop Med Public Health 3: 518-536

Sasa M, Tanaka H (1974) A statistical method for comparison and classification of the microfilarial periodicity. Jpn J Exp Med 44: 321-346

Sawyer TK (1975) Seasonal fluctuations of microfilariae in two dogs naturally infected with Dirofilaria immitis. Proc Heartworm Symp 1974, 16-17 March, 1974, Auburn, Alabama, USA. (Compiled Amer Heartworm Soc). 23-25

Tolbert RH, Johnson WEJ (1982) Potential vectors of Dirofilaria immitis in Macon County, Alabama. Am J Vet Res 43: $2054-2056$

Webber WAF, Hawking F (1955) Experimental maintenance of Dirofilaria repens and D. immitis in dogs. Exp Parasitol 4: $143-164$ 